\title{
The game itself?
}

\section{Towards a Hermeneutics of Computer Games}

\author{
Espen Aarseth \\ Digital Media Department, School of Art and \\ Communication, Beijing Normal University, Beijing, \\ China, and the IT University of Copenhagen, Denmark \\ aarseth@itu.dk
}

\begin{abstract}
In this paper, we reassess the notion and current state of ludohermeneutics in game studies, and propose a more solid foundation for how to conduct hermeneutic game analysis. We argue that there can be no ludo-hermeneutics as such, and that every game interpretation rests in a particular game ontology, whether implicit or explicit. The quality of this ontology, then, determines a vital aspect of the quality of the analysis.
\end{abstract}

\section{KEYWORDS}

Game analysis, game ontology, ludo-hermeneutics, game hermeneutics

\section{ACM Reference Format:}

Espen Aarseth and Sebastian Möring. 2020. The game itself?: Towards a Hermeneutics of Computer Games. In International Conference on the Foundations of Digital Games (FDG '20), September 15-18, 2020, Bugibba, Malta. ACM, New York, NY, USA, 8 pages. https://doi.org/10.1145/3402942. 3402978

\section{INTRODUCTION}

What is game hermeneutics and why would we need it? What does it mean to say that we understand a game? Is it enough to say that we understand a game when we can play it well? What does it mean to interpret games? And what about the other players? In a game of poker, the players are interpreting each other, but are they thereby interpreting the game? Does poker itself have meaning? Or is it producing new meaning every time it is played? Clearly, a distinction should be made between the paradigmatic structure of poker itself and the syntagmatic structure of the poker session, whereby one is producing the other (with the help of the players, or poker-robots). But is this the case for all games? Take, on the one hand, Dragon's Lair [25] the classic laser-disc actionadventure. Dragon's Lair contains a finite number of scenes, but the order of scenes varies between sessions. In this game, the number of variations is quite limited; given a little time and a few play-sessions all possible permutations can be produced very easily, and the game has given up all its secrets. Here, a textual hermeneutics can be applied unproblematically, and a game-specific hermeneutic seems

Permission to make digital or hard copies of part or all of this work for personal or classroom use is granted without fee provided that copies are not made or distributed for profit or commercial advantage and that copies bear this notice and the full citation on the first page. Copyrights for third-party components of this work must be honored

For all other uses, contact the owner/author(s).

FDG '20, September 15-18, 2020, Bugibba, Malta

(C) 2020 Copyright held by the owner/author(s).

ACM ISBN 978-1-4503-8807-8/20/09.

https://doi.org/10.1145/3402942.3402978

\author{
Sebastian Möring \\ Department for Arts and Media, University of Potsdam, \\ Potsdam, Germany \\ sebastian.moering@uni-potsdam.de
}

superfluous - or trivially similar to textual hermeneutics. On the other hand, in any truly massive multiplayer game like EVE Online [23] a particular observer cannot come near exhausting even a tiny fraction of all the possible trajectories; they are infinite, like space itself. Faced with ludic infinity, game studies need a hermeneutic theory that can account for both the philological incompleteness of the ludic object and the in-medias-res of the playing subject.

However, as the two examples show, the notion of games or even computer games is far too wide to comfortably fit into a single hermeneutic mold, whether textual or ludic. A highly likely reason for the lack of successful game hermeneutic theories at this point, just as the similar lack of narrative game theories until recently [7], is the lack of an ontological basis on which to build the ludohermeneutic theory. The hermeneutics of film (until the advent of CGI), literature and visual art all have stable ontological foundations. In those fields, it has not been necessary or even welcome to discuss the material, informational, formal and mental preconditions - they are given and therefore taken for granted. With the indefinable and problematic category of games, however [9], there exists no stable ontology (although sub-ontologies are possible, say, for mancala games, or card games), and therefore no viable ludo-hermeneutic theory has hitherto been created.

When we approach a game for the first time, we typically already have a preconceived, ontological notion of what kind of game it is. This does not imply that the player already has perfect knowledge of the identity of the object in question. This preconceived notion will guide or misguide the interpretation and may change in the gameplay experience which may affect and even change the ontology itself. For instance, when people start playing fourney [52] they are very likely to approach it as a singleplayer game. However, when encountering certain figures players may suddenly realize that they are actually playing a multiplayer game, and these figures are controlled by other human players. In this case, the first ontology is replaced by a second one which forces the player to reassess the game's identity and the basis for interpretation.

In this paper, we will first review previous attempts to formulate a hermeneutic game theory, and then we will present our arguments for why any such theory needs to be grounded in an ontological model as well as a general hermeneutics. Finally, we will discuss what a hermeneutic theory of games is and does, with a brief example of what a hermeneutically self-aware method of game interpretation might look like. 


\section{PREVIOUS DISCUSSIONS OF GAME HERMENEUTICS}

The question of the interpretability of computer games unfolded early on in game studies. In her pioneering dissertation, Buckles [19] notes that "the process of reading interactive fiction" implies a form of self-interpretation [19, p. 4]. This is reminiscent of reading conventional literature such as the classical Bildungsroman, which itself serves as a form of self-interpretation for mainly adolescent audiences. On the other hand - presciently describing the phenomenon that was much later labeled 'theorycrafting' - Buckles frames this self-interpretation as practicing "philosophy of science," which involves the interpretation of game events and "distancing oneself from one's own preconceptions, [while] testing whether one's interpretation of the event is actually correct, and forming a new interpretation if it is not" [19, pp. 4-5]. Hence, Buckles seems to distinguish between the interpretation of interactive fiction as text interpretation as well as an interpretation of this interactive fiction as a nonlinear dynamic object.

In 1994 one of us [1] suggested two points which should be considered when formulating a game hermeneutics. The first point regards the primacy of the praxis of gameplay as an interpretive process. The second one regards the mechanical game object of the computer game which forms the basis of such interpretive processes. Aarseth proposed that a hermeneutics of nonlinear texts requires "a concept that implies both more and less than reading and redefines literary satisfaction as well as hermeneutic behavior" [1, p. 67] which later has been reframed as "real-time hermeneutics" [3, p. 5]; a concept which can be misunderstood as referring to so-called realtime games only. In his methodology of game analysis, Aarseth [3] offers a systematic meta-method of game analysis as a self-reflective hermeneutic practice which takes play and non-play activities into account; a distinction which Calleja later calls micro-involvement and macro-involvement in gameplay [22]. Aarseth puts a strong emphasis on the praxis of gameplay as a form of analysis and hermeneutic when he says "to show that we understand a game, all we have to do is to play it well" [3, p. 5]. This mode of interpretation is primary to narrative or text interpretations since computer games are the "hermeneutic Other of narratives; the alternative mode of discourse, bottom up [sic] and emergent where stories are top-down and preplanned. In simulations [computer games], knowledge and experience is [sic] created by the player's actions and strategies, rather than recreated by a writer or moviemaker" [4]. Therefore, the postulated hermeneutics of computer games can also be understood as a hermeneutics of the interplay between mechanics and semiotics (see also [2]; [3]; [26]; [6]).

While Aarseth focuses on the interpretation of the gameplay process, Murray seems to focus on computer game interpretations as text interpretations. Her prominent suggestion is that "games can also be read as texts" [43, p. 143] one page before she offers her often discussed (cf. [27], [18]; [49]; [14]; [41]) interpretation of Tetris as "... the perfect enactment of the overtasked lives of Americans in the 1990s..." [43, p. 144]. Given that Murray uses the notion of "reading" in the sense of "interpreting," this suggests that she also assumes that a mode of game interpretation is a form of text interpretation or text hermeneutics. This underlying assumption sparked some controversy in that Eskelinen dismisses Murray's interpretation as a projection of some content onto the game without making sense of the game itself. Specifically, he criticizes that Murray does not "study [...] the actual game," and that her interpretation is a projection of her "favorite content" on the game which however does not teach the reader "anything of the features that make Tetris a game" [27]. Bogost, on the other hand, argues that Murray's "interpretation is certainly a viable one. It suggests the variety of interpretations available to players of the game" [17, p. 100]. He suggests that Murray's interpretation lacks a clear reference to gameplay and the game's "unit operations" while it takes into "account a larger system [e.g. modern work conditions] that the game represents in smaller part" by means of simulation [17, p. 101]. Apart from a text interpretation of computer games and interpretations in the process of gameplay, it appears that Bogost suggests a third relation between interpretations and games. As simulations of smaller subsets of the world, games interpret the world in one way or another. Bogost later tries to make this idea productive with his concepts of "persuasive games" and "procedural rhetoric" [18].

Distinguishing between how non-ergodic art versus computer games are interpreted, Eskelinen famously said "in art we might have to configure in order to be able to interpret whereas in games we have to interpret in order to be able to configure" [27]. Eskelinen hereby distinguishes between two kinds of interpretation for two different kinds of artworks. The interpretation of non-ergodic art (e.g. paintings or operas) requires the interpreter to configure her pre-understanding with the work itself until it begins to make sense in light of the pre-understanding - a process which describes successful interpretation. Ergodic art such as computer games, on the other hand, first requires the user to do something with the artwork, i.e. configure it in order to see how the game reacts to a specific input. The relation between user input and game output can then be interpreted as useful, successful, failure etc. which might or might not lead to further player input and start a hermeneutic gameplay circle anew.

Arsenault and Perron construct a general model of the gameplay process which they wittily call the magic cycle. The model is a response to the lacking "distinction between the process of playing a game and the game system itself" [12, p. 109]. At the core, the model consists of two heuristic spirals (gameplay and narrative) and one hermeneutic spiral (interpretation of hidden meanings, see also Murray [43]) which are all interconnected in the gameplay process.

It is problematically conspicuous that Arsenault and Perron consider only the third spiral as hermeneutic whereas the other two spirals are labeled heuristic. They do not explain why they chose the latter concept, nor what it denotes. The notion heuristic is of Greek origin and means to find or to discover by chance, and in scientific research commonly refers to an unstructured process of investigation (often trial-and-error) with little guarantee for useful results. It is also used to metaphorically frame an everyday problem-solving task (cf. [32, pp. 381-382]; [41]). The Cambridge Dictionary of Philosophy places heuristics mostly in the corner of computer science being a method for reducing the complexity of computational problems and the resources needed to solve it [13].

Hence, Arsenault and Perron seem to think of hermeneutics merely in terms of textual interpretation, and use heuristics for 
solving practical problems and tasks like understanding how a game works. Thus, their model has two concrete problems. First, their notion of hermeneutics is much too narrow compared to its contemporary denotations, which cover all sorts of practical understandings of the world in addition to text hermeneutics. Second, it favors a concept (heuristic) that is prominent in scientific investigation and computational problem solving over a concept which also accounts for the human capacity of understanding how to deal with most everyday situations. Computer gameplay normally does not consist of solving scientific problems, instead it consists of the practical challenge of playing. And typically, this challenge hardly exists as a problem to be solved since most game players are already familiar with their computer games of choice. In puzzles of course players have to solve puzzle problems (and not scientific problems) but also in the case of puzzles players usually have previous knowledge of how to puzzle, so they are never faced with a completely new problem. Even when faced with a new game, players typically have at least some knowledge of the gameplay from previous encounters with similar games. In other words, the concept of hermeneutics is capable of covering all three of Arsenault and Perron's spirals. As we will point out, hermeneutics ranges from an interpretation involved when practically doing something (like playing a game) to interpretation in the sense of deriving theoretical meaning from some object or text (interpreting a text, or interpreting a game's textual meaning). The former form of interpretation is involved in Heidegger's notion of dealing with something or the world in a ready-to-hand manner and the latter form of interpretation is involved in Heidegger's notion of dealing with something which is present-at-hand [32, pp. 102-107].

Contrary to Arsenault and Perron, Arjoranta [11] and Karhulahti [35] consider the act of gameplay as hermeneutic. Arjoranta [11] is the first to point out explicitly the need for a gameplay hermeneutics which does not only account for the reading of textual and visual signs but which accounts for the characteristics of computer games like their interactivity and temporality. He approaches Aarseth's [3] notion of real-time hermeneutics from the angle of time "in order to understand how temporality affects the understanding of games" [11]. Arjoranta criticizes Aarseth's notion of "real-time" in order to account for the immediate feedback of the computer game with which a user engages, and posits that real-time can be experienced in different ways; it is not necessarily immediate. Following Gadamer, interpretations of non-ergodic artworks can be enriched by "temporal distance" between the interpretation and the first occurrence of an interpreted object [11]. He assumes that the meaning of such a work can be enriched by all other previous cultural interpretations. Yet, he contends, the idea of real-time game hermeneutics does not allow for this temporal distance. Arjoranta seems to imply a twofold hermeneutics consisting of player interpretations during gameplay and after-the-fact (distant) interpretations involving cultural discourse. Arjoranta appears to distinguish between micro-involvement and macro-involvement in computer gameplay, too, although he initially appears to favor after-the-fact interpretations situated in a cultural discourse; why else would he find the notion of real-time hermeneutic problematic? However, in his conclusion, Arjoranta partly dismisses his own approach and poses two new questions relevant to the present approach: "First, what is the meaning of the game itself as an object of understanding? And second, what interpretations does the player make during the game?" [11].

Karhulahti suggests a "double hermeneutic" [35] for the interpretation of computer games and specifically adventure games which resembles, but does not address, Arsenault and Perron's distinction between the heuristic gameplay spiral and the heuristic narrative spiral. He proposes that playing computer games involves two hermeneutic circles. The ludic hermeneutic circle refers to the player's ludic understanding of the game at play. This implies that the player configures the game and thereby affects the current game state (e.g. opening up new game spaces, new rooms or changing strategic situations). Karhulahti refers to this as "inducing interpretation that aims at generating ludic understanding of game elements" [35]. On the other hand, there is what Karhulahti calls the poetic/aesthetic hermeneutic circle that is concerned with "acquiring and interpreting narrative or other aesthetic literary information" [35]. Since the interpreter does not change the narrative (as in rewriting) but just chooses from given options, Karhulahti calls this interpretation non-inducing. Adventure games lend themselves to the poetic/aesthetic hermeneutic circle: "A comprehensive understanding of the adventure game object does not therefore reflect solely on its ludic call to overcome challenges and on its narrative appeal to restore behavior but also on its facet of poetic reading" [35].

According to Karhulahti [35], in kinesthetic games (also called time-critical action games by Pias [48], or "haste"-based by Elverdam \& Aarseth [26]), the ludic hermeneutic circle will be in the foreground. Thus, Karhulahti suggests a distinction between games that favor a textual hermeneutic and games that favor a ludic hermeneutic. To Karhulahti, the ludic understanding of a game is a doublyinterpretational process which he sees as consisting of the fact that the interpreter influences the interpreted while interpreting:

"The 'double hermeneutic' label [...] does not [...] derive solely from its dual modality [ludic and aesthetic interpretation] but also from the particular two-way affectivity of ludic interpretation. A ludic interpretation is not only an object-oriented mental configuration but also a potential object-altering material configuration" [36].

However, this is not a doubly interpretational process. Influencing the interpreted while interpreting only means that an interpreter interprets a process (which she is part of) rather than an object. In addition, Karhulahti seems not to account for the fact that the interpreter herself is part of the interpreted and mistakes this for a double hermeneutic which can easily be misunderstood. If there is any doubly-interpretational process going on, then it is the simultaneous self-interpretation of the player and the player's interpretation of the game process which mutually influence each other. The problem with this double-hermeneutics is furthermore that it allows to understand driving a car as a double-hermeneutics, too, and thus, in the long run, turns hermeneutics as such into a double-hermeneutic process. A viable criticism of Karhulahti's double-hermeneutics is that it is not game-specific. Consequently, the only double-hermeneutics that Karhulahti is suggesting is the distinction between a practical hermeneutics of gameplay and a text (or aesthetic/poetic) hermeneutics. We will later see that the problem Karhulahti is actually dealing with is that between the 
interpretation of a praxis (or a process) as something which is experienced from a first-person perspective versus the interpretation of an object which is present-at-hand as something which is looked at from a third-person perspective (cf. [41]).

\section{GENERAL HERMENEUTICS}

One of the central problems of previous discussions of game hermeneutics is that most approaches are not properly grounded in existing hermeneutic theories such as those by Heidegger and Gadamer. We therefore want to revisit some central ideas from hermeneutic theory because it offers useful distinctions on the way to a game hermeneutics.

Until today hermeneutics is commonly regarded as a practice of text interpretation. From this perspective, hermeneutics is rooted in the exegesis of biblical texts in order to analyze the word of God, and to apply it as a guideline for a life well-lived. Contemporary hermeneutics scholarship agrees that early roots of hermeneutics go even back to Greek antiquity where the epics by Homer were systematically analyzed with "a method of nonliteral interpretation of the authoritative texts [...] aiming at a deeper sense, hidden under the surface - hypónoia, i.e., underlying meaning." This method has become known as allegoresis [39]. If Arsenault and Perron [12] refer to game hermeneutics as finding a hidden meaning it seems they refer to this notion of hermeneutics.

Among the most influential theorists of modern hermeneutics are Friedrich Schleiermacher, Wilhelm Dilthey, Martin Heidegger and Hans-Georg Gadamer. While critics mention "a general hermeneutics had existed at least two centuries before Schleiermacher" [39]. Schleiermacher is accepted as the first to distinguish between hermeneutics as a "methodology of text processing and the theory of human understanding as such" [10]. In doing so Schleiermacher distinguishes between a narrow idea of hermeneutics as literary or text interpretation and a broad idea of hermeneutics which designates human understanding in general. Dilthey, a follower of Schleiermacher, set out to characterize the German Geisteswissenschaften (humanities) and raises hermeneutics to the rank of its central method. While the primary epistemological mode of the natural sciences is to explain (erklären), the humanities' mode is understanding (verstehen) (cf. [10] and [39]).

With Heidegger's Being and Time [32] hermeneutics takes a new turn, and is no longer merely considered the epistemological method of the humanities or a method of text interpretation. Hermeneutics is now considered the central way of how humans exist in the world [20]. For Heidegger, a human being is always already understandingly-in-the-world in that humans always already tacitly understand their world, its specific affordances, limitations, and conditions by just dealing with it in their everyday lives. Heidegger expert, Dreyfus, explains this as follows: "To understand a hammer [...] does not mean to know that hammers have such and such properties [...] understanding a hammer at its most primordial sense means knowing how to hammer" [24, p. 184, italics in original].

Hence, understanding how to hammer neither implies one's capacity to understand the cultural meaning of a hammer in a given discourse, nor the capacity to name its scientific characteristics. In Heidegger's hermeneutics understanding is first of all practical and it is the prerequisite of all theoretical understanding - since humans first and foremost exist in their everyday copings with the world and not in a mode of scientific interpretation of their world. Interpreting Heidegger, Dreyfus writes "understanding reveals some actions as doable, as making sense, and others as not" [24, p. 185]. This primordial practical understanding of the world, then, is the condition of possibility of text interpretation (e.g. in terms of an allegoresis), or a scientific interpretation of the world. Heidegger's hermeneutics consists of a complex structure of which we will only refer to those elements which relate directly to our argument. Depending on the translation Heidegger mentions either "leeway" [32, p. 185] or "room for maneuver" [24, p. 186] as an essential element of understanding since every human being understands tacitly or cognitively its possibilities to be. If there is more than one option to choose from then we can speak of a room for maneuver. The German translation interestingly is Spielraum (literally "space of play"). It is Gadamer who makes this play element in hermeneutics productive as we will show in a bit. With Heidegger, we can furthermore distinguish between an authentic and inauthentic understanding. A human being understands how to exist inauthentically when only realizing those options which are pre-interpreted as the most common way to exist [38]. On the other hand, a human being understands how to be authentically when it manages to realize its very own possibilities to be. Eventually, Heidegger distinguishes between three types of understanding: Coping, interpreting, and asserting [24].

- Understanding as coping describes the "unreflective, everyday, projective activity such as hammering" and it "becomes explicit in the practical deliberation necessitated when a skill failed to suffice, and what has thus become thematic" [24, p. 195]. To give an example from computer gameplay: We are able to play Super Mario World [44] without needing to cognitively reflect on what we are doing. But this would not work with Kaizo Mario World [51], the famous and overly difficult modification of Super Mario World. Clearly, coping, when successful, is different from a heuristic in that it proceeds in an unreflected way.

- Understanding as interpreting, then, means to make sense of that which cannot be coped with on the first level of understanding [24]. This happens when we realize that we cannot play Kaizo Mario in the self-presumed way in which we play Super Mario World.

- Understanding as asserting, then, means to thematize that which cannot be coped with and to find e.g. reasons for this - such as the game is too difficult, the player is not skilled enough, or the simulated platforms are too far apart in order to make Mario jump from one to the other, etc.

In effect, these three stages of understanding describe the process of how something which is first experienced as ready-to-hand changes its mode into being experienced as present-at-hand; i.e. it changes from being experienced in use (first-order experience or first-person experience) to being experienced while being looked at (secondorder experience or third-person experience). From this brief review of Heidegger, we see that his hermeneutics works well to describe the processes of understanding, interpreting and asserting in computer gameplay, and also that Heideggerian hermeneutics applies 
the notion of Spielraum (leeway or room to move) to explain how understanding works.

Following this, Gadamer makes the concept of play central and productive in his hermeneutics. For Gadamer, the artwork only comes into existence when it is appreciated or interpreted by an observer; i.e. when it is part of a hermeneutic process. No matter if the artwork itself is an object (e.g. a painting) or a process (e.g. a theater play or interactive art), the interpreter engages with it from a third-person perspective and engages with it in a hermeneutic circle that has the form of the to-and-fro movement of a game at play [30]. For Gadamer, the subject of a game is not merely the human player but the game itself [30]. As a matter of fact, a game for Gadamer is first and foremost a form that needs a medium to perform its characteristic movement [30]. This medium can be playing humans or animals, but also natural phenomena such as waves or light, or even the process of interpretation in a hermeneutic circle [30]. Consequently, for a game to come to itself it is necessary that its players understand how to keep a game at play, and therefore games have the existential requirement that their players keep it at play by interpreting the tasks provided by the game in a way that maintains the game. A different way to keep a game at play than preventing it from a premature game-over is to keep exploring for its possibilities to unfold. The same goes for all other artworks: If they fail to keep their audience engaged in a process of ongoing interpretation they cease to be artworks. With this in mind, it appears that Heidegger's hermeneutics is focusing on the point of view of an interpreting human subject whereas in Gadamer's hermeneutics the subject of interpretation is the game or the game of interpretation itself.

While interpretation and hermeneutics might have the form of play, following Heidegger and especially Gadamer (or even Derrida), this does not mean that the question of game hermeneutics is solved here. Computer game-play is often understood as a cybernetic feedback loop and the Gadamerian framing of the hermeneutics of artworks as a hermeneutic circle seems to tie in very well with cybernetics. However, conceptualizing computer game-play merely as a feedback loop is not sufficient in order to understand how the hermeneutic to-and-fro works in the case of specific computer games. In order to account for the specificity of computer games as media technologies and as technological practice, we must first have a proper ontology of computer games. This proposal is discussed in the following section, after which we will account for the differences among ludic objects and lay out their consequences for the possibility of a ludo-hermeneutic theory.

\section{PRECONDITIONS FOR A LUDO-HERMENEUTICS}

A hermeneutics of ludic objects and processes, like any other hermeneutics, presumes an ontological basis as mentioned above. An ontology is a generalized set of principles based on observations of an empirical field - in other words, a theory of relevant phenomena and their relations - whereas a hermeneutics is a method of interpretation directed towards a specific, historically delimited object or situation. Before the interpretation can take place, the phenomenon must be identified as belonging to a class or genre for which the method is appropriate. In other words, first comes the ontological identification, then the hermeneutics, at least on the receiving end. An enologist, preparing to blind taste wine, will not be able to make sense of goat milk or crude oil within their expert framework. A connoisseur of horror films will similarly be confused by Cabin in the Woods, which appears to be a classical/clichéd horror movie, but then reveals itself to instead be science fiction in a brilliant illustration of what Brian McHale [40] refers to as the ontological dominant of science fiction (and postmodernism).

The fundamental challenge to establishing a ludo-hermeneutics is that games are not one type of phenomenon. This should warn us that ludo-hermeneutics, at best, must be a family of hermeneutic theories or models rather than one. An alternative would be a hermeneutic theory that is on a high enough level of abstraction that all kinds of games are covered, but then we also face the risk that it is a hermeneutics of everything - and therefore of nothing in particular. A synthesis of these two alternatives is a general, high-level template, which can be expanded into several targeted hermeneutic models in each ludic subdomain.

The execution of such a synthesis would be a dynamic hermeneutic method which has a game session and a specific ontological perspective as input, and completes itself upon playing and understanding (or in occasional addition, as a critical assertion).

Just as in literary, cinematic or pictorial analysis, where the analyst describes important features of the text/image (typically the plot or tableau) before they evaluate and interpret it, so should a ludo-analyst describe the ontological makeup of the game before commencing the critique. However, it is more common to fasttravel over this by instead throwing down a genre label (e.g. RPG, FPS) and then a summary of the scenario or of the plot of the main storyline (if there is one). By glossing over the ontological specificities, however, the analyst not only demonstrates a lack of curiosity for the ludic (as opposed to textual) aspects, but also blinds the analysis from discovering any potentially unique aspects of that particular ludic object. An analysis that places all weight on the textual aspects will not be able to address the hermeneutic dimension of playing, or what it means to be a player of that game.

If by "game" we simply refer to the textual elements of the ludic object, then this omission would pose no problem, however, we are then using the word game metonymically, to refer to a part of what the ludic object is. We are no longer addressing - much less analyzing - the game of the "game." Instead, we are addressing and analyzing the uninformed spectator's view, the game's textual/audiovisual output, and not engaging with the primary locus of ludic meaning, which is the player's hermeneutic behavior - the process of making sense of the game. Games still do produce meaning on that secondary, spectatorial level which should be studied also, but the two are very different. The first spectator is always the player herself, but ludo-spectatorship is a broad spectrum or field of different types and positions of engagement, which should not be conflated [8].

Just like the academic meme that "everyone has a theoretical grounding, even if they don't make it explicit," every game scholar has an ontological basis for their analysis, even if they don't declare it or reflect on it. But unless forced to confront their implicit ontology, game scholars - given the extremely vague nature of their objects of study - typically make the fallacies of overreaching or over-generalizations. A highly useful exercise is to always take the time to describe the ontological profile of the games we are 
discussing, even and perhaps especially when they are known to everyone like Tetris or chess. Reminding ourselves what we are looking at can make us see it anew, and thus as a phenomenon in its own right and not just as a handy example of what we want to discuss.

What game ontology should we use? There are already quite a lot of them (e.g. [54]; [56]; [21]) and while they never seem to address, much less engage each other, most provide a helpful stage of reflection, as the first phase of interpretation. For the purposes of this article, game ontology is an ongoing scientific dialogue that still has a long way to go, and therefore should not be pinned down at this moment. As long as a game's ontology is not taken for granted, our purpose has been served. The ludontology assumed in this article is laid out in Calleja \& Aarseth [9] and posits a game as a four-dimensional field composed of mental activity (the player and her community) a semiotic system (the audio-visual or tactile communicative aspects), a mechanical system (influencing the game state) and a materiality (the physical environment in which the game is embedded, including the players' bodies).

Is a game different from a text, or are they the same? This question presupposes an idea of what a text is. Here we have many alternatives: Text could refer to a philological object of ordered (typically linear) orthographic signifiers, or it could be a post-structuralist web of meaning, or it could be any semiotic object or corpus as espoused by studies of art (such as a poster, a film, a sculpture, a city, or any collage or semiotic assemblage). In this context, it does not really matter much which one we select so long as we recognize its implied primacy of a semiotic focus. A game, then - understood as a mechanical system and not a social process - is not a text. A game is a type or family of phenomena that may use texts and semiotic codes for ludic purposes, but in different ways depending on the game's ontology. Some games are purely text-based (e.g. riddles, classic detective or crime mysteries), meaning that they contain their mechanical structures either implicitly (detective story) or explicitly (choose your own adventure). Others are predominantly textual (hyperfiction, Twine games) and others are hybrids that rely on text and mechanics equally (adventure games). As long as we can describe the mechanical system independently of the textual or diegetic elements (e.g., as a system of formal connections), we can maintain the difference between textual representation and mechanics, and the functional distinction between text and game is preserved. In the few cases we cannot do this (detective novels and verbal role-playing games) then we simply invoke the ontological category of fiction-based games, or games of mimicry [21].

\section{A METHOD OF LUDIC INTERPRETATION}

Each game (or, depending on how we delimit games, game genre; see [31]) comes with its own implied hermeneutics. This hermeneutics is its own circular process or interpretive "feedback loop" [2], by which we play, learn and grasp. If a game offers more than one playing process (a set of interrelated mechanics engaged by a player), is it still only one game? And if two different games have the same playing process, are they not the same game? Clearly, there are examples of both alternatives: World of Warcraft [16] offers many different playing processes, from auction-house trade to battleground competitions. As players can easily devote themselves to one and not the other, these are, in fact, two different games in the same 'game' or virtual world. On the other hand, in football (soccer, to Americans), playing as a goalkeeper is a very different playing process than playing as a striker, but it would be hard to claim that football is two different games. Perhaps the crucial difference between these two examples is that in football the players work together on the same project and in the same process, whereas in WoW they do not. On an abstract level, we can define 'playing the same game' as 'engaging the same set of mono-ludic mechanics.'

Also, Counter-Strike [53] is typically seen as one or the same game, although it makes a lot of difference to the players' processes what sort of level or map is being played. Is Counter-Strike on the Dust 2 map the same game as Counter-Strike on Aztec? In fact, it is more complicated; some Counter-Strike levels are infinitely more popular than others, and the most popular levels embody what Counter-Strike is as a game. As the name suggests, Dust 2 (2001) was not an original Counter-Strike map but became the most popular map. Through this popularity and from then on, Dust 2 helped define what an ideal Counter-Strike map should be like (see [34]). Even though Counter-Strike existed as a game before Dust 2 was made, it became more itself as a result of Dust 2. We might think of such a process as exceptional, but most games are created gradually, in a creative testing loop (cf. [29]; [46]; [42]) or even more slowly, over the centuries or millennia, like chess and Snakes and Ladders. As the game is played, it becomes itself and changes itself in an endless double hermeneutic feedback loop between the player and the game; both are played by the other, and both change - the player more quickly, the game more slowly. The game itself has, or better, is a hermeneutic method, whereby it becomes itself via repeated play. Ironically, however, the game encountered by the player is not the hermeneutic process, but its ontological result - its here-and-now. The exceptions to this argument would be game design processes and formation of house-rules etc., but in computer-mediated play (and unlike, say, board-gameplay), these formative and transformative practices are precisely exceptions, and therefore not commonplace play practices [5].

What has been called game hermeneutics (see [11], [36]), is rather the player's hermeneutics: the process of becoming-a-player. This is also the uncovering of the game's ontology; the realization of what it takes to be a player of that particular game, and of getting to know the game's here-and-now.

Let's apply this understanding to a simple game analysis example. Fallout: New Vegas (F:NV, [45]) is one of the most intriguing and rich ludo-narrative works in recent years. It belongs to the long-running Fallout series (1997-) and is a zoned, open-world leveling-up game using the Fallout-series S.P.E.C.I.A.L. avatar-development system. As a game system, it is virtually the same as Fallout 3 [15], with minor modifications. As a post-apocalyptic game world set in a future US southwest desert landscape, however, it is much more detailed and rich than its predecessor, and the various factions, quests and characters are more complex and many-faceted, depending on what allegiances and playstyles the player chooses. The player has the role-position of the Courier, near-fatally shot in the head and left for dead, with no clear reminiscence of their current mission. A cornucopia of interesting choices awaits, and it would be close to impossible to analyze satisfactorily all the possibilities for action in this article. For a fascinating and contrasting alternative to this 
openness, see Leino's [37] existential account of being stuck in a $F: N V$ "death loop."

Instead of a full analysis, let us look at a particular encounter with a particular character of the game. Caesar, the leader of Caesar's Legion, is a brutal tyrant who vies for control of the desert wasteland against various other powerful clans and alliances. The Courier may get close to Caesar and become a collaborator, run quests, and so on, or may decide to fight Caesar and his Legion instead. Given the Legion's brutality and horrific treatment of the other wasteland inhabitants - including the use of crucifixion this might be the easiest choice. However, Caesar is a fascinating character to talk to and explore, and any adverse strategy will not accommodate this option. But on a more epic scale, one might also think twice before helping the worst tyrant take over the entire region. So, what to do? The game is a singleplayer experience that allows near-unlimited saves, and so one is free to follow more than one branch of the plotted network. The player could first choose to go along with Caesar and get the experience of the quest-line until (perhaps) a sense of ludo-morality brings one to the point of return, and one recedes to a previous, morally safer save point where the player proceeds to fight or ignore Caesar instead. Fighting Caesar will eventually allow the competent player to kill him, thus ridding the world of a dangerous tyrant. However, for the end-game this turns out to be not very effectual and instead paradoxical, as Caesar is succeeded by an even more murderous lieutenant, Legate Lanius (Lanius is Latin for butcher).

The hermeneutic method we can use for exploring Caesar and the Caesar's Legion characters and quests is defined by the game and the player in communion, and would be very different from, say, analyzing an MMO game like Elder Scrolls Online [55] or a linear quest game like Final Fantasy VII [50]. It could on the other hand be very similar to the same player analyzing Fallout 3 [15]. The method is flexible in terms of the game landscape, but limited by the player's genre-based gameplay habits (ludo-habitus), game-dependent choices of special skills, and the order in which the quests are pursued. It is also dependent on the game's interpretive community, and on what they have made available in resources for the player, e.g. as online videos, walkthroughs, or general information.

For the game scholar or academic game critic, however, this method is not sufficient. Their assertive goal is to present their communities with a verbal account of their ludo-hermeneutic insights, not just with the fact that they have attained an understanding of the game in the shape of a high score or similar. For them, and unlike, say, a musician interpreting a musical score or an actor interpreting a role on stage, the process of asserting the results of the investigation becomes the main effort of the investigation itself. Thence, interpretation becomes the formulation of that interpretation, rather than the interpretation itself.

Also, scholars hardly ever interpret just for the sake of interpretation; there is always an ulterior motive, typically in the shape of a research question. Critics, similarly, are motivated by normativity: asserting some particular quality in the present work is worth pointing out. In both these types of cases, the method will be dictated by the motive, and will therefore be as idiosyncratic as the motive itself. Game hermeneutics, then, is the meeting of a particular game and a particularly motivated player, and, depending on the motive, will result in a particular, critical enunciation. There can be no ludo-hermeneutic method as such, only pragmatic methods serving particular purposes. A catalog of such purposes, however, is beyond our present scope. The universal method that can be formulated here is the identification of the game's ontological nature. This is the first step of ludo-hermeneutics, and the only step that implicitly or explicitly is necessary. The rest depends on game type and player motivation. Game types form interpretive communities [28] and interpretive communities motivate players to develop specific methods of interpretation, assertive or not.

\section{CONCLUSION: FIRST COMES THE ONTOLOGY, THEN THE HERMENEUTICS}

The practices of ludo-hermeneutics presume a specific ontological basis, either explicitly or implicitly. This holds true for players, critics, and theorists alike. As we saw in the fourney example in the introduction of this paper, there is of course a to-and-fro movement between these two aspects, the abstract and the particular, where playing leads to increased ontological understanding. A particular process of interpretation cannot take place without an underlying ontological model, however weak it may be initially. There is no universal gameplay that pertains to every kind of game, and there is no hermeneutic method of game analysis as such; only gamespecific or genre-specific depending on how we conceive of the game/genre (token/type) demarcation.

Consequently, any ludo-hermeneutic theory which contents itself by framing all games as a cybernetic or hermeneutic feedback loop misses the point because such models unintentionally make all games alike, which they are not. Since approaches to game hermeneutics are necessarily diverse due to the diversity of computer games, a possible way to learn more about game hermeneutics could be to meta-review a large collection of individual gamehermeneutic analyses which make their underlying ontology explicit, and compare and collate those ontologies.

Or, instead of relying on existing ontologies, we could make a new and better (meta-) ontology, whereby ontological descriptions for particular games and game genres could be minted in a more systematic and less blurry way than what we have seen so far. With such a tool, the formal, structural and syntactic differences between different games could be swiftly identified and set aside, leaving the scholar or critic to get on with the perhaps more interesting questions of ludic meaning and interpretation.

\section{ACKNOWLEDGMENTS}

This research was partially funded by the European Research Council (ERC) under the European Union's Horizon 2020 research and innovation programme (Grant Agreement No 695528 - Making Sense of Games). We would like to thank Ryan Christopher Wright, Lars Pinkwart and Frederik Bakkerud for excellent editorial assistance.

\section{REFERENCES}

[1] Aarseth, Espen. 1994. "Nonlinearity and Literary Theory." In Hyper/Text/Theory, Ed. George P. Landow, p 51-86. Baltimore and London: The Johns Hopkins University Press.

[2] - - . 1997. Cybertext: Perspectives on Ergodic Literature. Baltimore, Md: Johns Hopkins University Press. 
[3] - - - 2003. "Playing Research: Methodological Approaches to Game Analysis." In Game Approaches / Spiel-Veje. Papers from Spilforskning.Dk Conference, August 28.-29. 2003, 1-7. Melbourne. http://courses.ischool.utexas.edu/megan/ MeganCollection2/files/1472/Aarseth.pdf.

[4] -- - 2004. "Genre Trouble." In First Person: New Media as Story, Performance, and Game, edited by Noah Wardrip-Fruin and Pat Harrigan, 45-55. Cambridge, MA: MIT Press. https://electronicbookreview.com/essay/genre-trouble/.

[5] - - . 2007. "I Fought the Law: Transgressive Play and the Implied Player." In Situated Play, Proceedings of DiGRA 2007 Conference, 24-28. http://www.digra org/wp-content/uploads/digital-library/07313.03489.pdf.

[6] - - . 2011. "Define Real, Moron! Some Remarks on Game Ontologies." In DIGAREC Keynote-Lectures 2009/10, edited by Stephan Günzel, Michael Liebe, and Dieter Mersch, 50-69. DIGAREC Series 6. Potsdam: Potsdam University Press.

[7] -- - 2012. "A Narrative Theory of Games." In FDG 2012 Proceedings of the International Conference on the Foundations of Digital Games, 129-33. Raleigh, North Carolina: ACM Press. doi:10.1145/2282338.2282365.

[8] - - - 2017. "Spec Ops: The line between player and spectator in ludic entertain ment." Paper presented at Spectating Play, University of Tampere.

[9] Aarseth, Espen, and Gordon Calleja. 2015. "The Word Game: The Ontology of an Undefinable Object." In FDG. http://www.fdg2015.org/papers/fdg2015_paper_51. pdf.

[10] Ahrens, Rüdiger. 2008. "Hermeneutik." Edited by Ansgar Nünning. Metzler Lexikon Literatur- und Kulturtheorie: Ansätze - Personen - Grundbegriffe. Stuttgart: Metzler.

[11] Arjoranta, Jonne. 2011. "Do We Need Real-Time Hermeneutics? Structures of Meaning in Games." In Think Design Play: The Fifth International Conference of the Digital Games Research Association, edited by Copier Marinka and Waern Annika. Hilversum, the Netherlands: DiGRA/Utrecht School of the Arts. http //www.digra.org:8080/Plone/dl/display html?chid=11310.17396.pdf.

[12] Arsenault, Dominic, and Bernard Perron. 2009. "In the Frame of the Magic Cycle The Circle(s) of Gameplay." In The Video Game Theory Reader 2, edited by Bernard Perron and Mark J.P. Wolf, 109-33. New: Routledge.

[13] Audi, Robert. 1999. The Cambridge Dictionary of Philosophy. Cambridge, UK; New York, NY: Cambridge University Press.

[14] Begy, Jason. 2011. "Experiential Metaphors in Abstract Games." In Proceedings of DiGRA 2011 Conference: Think Design Play. Hilversum, the Netherlands: Digital Games Research Association DiGRA. http://www.digra.org/wp-content/uploads/ digital-library/11301.51130.pdf

[15] Bethesda Game Studios. 2008. Fallout 3. [Microsoft Windows; PlayStation 3; Xbox 360]. Bethesda Softworks.

[16] Blizzard Entertainment. 2004. World of Warcraft. [Windows PC et. al.]. Blizzard Entertainment.

[17] Bogost, Ian. 2006. Unit Operations. 1. MIT Press paperback ed 2008. Cambridge, MA: MIT Press.

[18] - - 2007. Persuasive Games. The Expressive Power of Videogames. Cambridge, MA: MIT Press.

[19] Buckles, Mary Ann. 1985. "Interactive Fiction: The Storygame 'Adventure."' $\mathrm{PhD}$ Thesis, University of California at San Diego.

[20] Burkard, Franz-Peter. 2008. "Hermeneutik." Edited by Peter Prechtl and FranzPeter Burkard. Metzler Lexikon Philosophie: Begriffe und Definitionen. Stuttgart Metzler.

[21] Caillois, Roger. 2001. Man, Play, and Games. Translated by Meyer Barash. Urbana: University of Illinois Press

[22] Calleja, Gordon. 2011. In-Game. From Immersion to Incorporation. Cambridge, MA: MIT Press.

[23] CCP Games. 2003. Eve Online. [Windows; Mac OS X]: CCP Games.

[24] Dreyfus, Hubert. 1991. Being-in-the-World: A Commentary on Heidegger's Being and Time, Division I. Cambridge, MA: MIT Press.

[25] Dyer, Rick. 1983. Dragon's Lair. [Z80]. Cinematronics.

[26] Elverdam, Christian, and Espen Aarseth. 2007. "Game Classification and Game Design." Games and Culture 2 (1): 3-22. doi:10.1177/1555412006286892.

[27] Eskelinen, Markku. 2001. "The Gaming Situation." Game Studies. The Internationa fournal of Computer Game Research 1 (1). http://www.gamestudies.org/0101/ eskelinen/.

[28] Fish, Stanley Eugene. 2000. Is There a Text in This Class? The Authority of Interpretive Communities. 11. print. Cambridge, Mass.: Harvard Univ. Press.
[29] Fullerton, Tracy. 2008. Game Design Workshop. A Playcentric Approach to Creating Innovative Games. 2nd ed. Amsterdam; Boston: Elsevier Morgan Kaufmann.

[30] Gadamer, Hans-Georg. 2004. Truth and Method. 2nd, ed. ed. London; New York: Continuum.

[31] Grabarczyk, Pawel and Espen Aarseth, 2017. "Games, genres, and infra-games: what are we looking at when we address games?" paper presented at CEEGS 2017.

[32] Heidegger, Martin. 2008. Being and Time. New York: HarperPerennial/Modern Thought.

[33] Honderich, Ted. 2005. The Oxford Companion to Philosophy. 2nd ed. Oxford; New York: Oxford University Press.

[34] Johnston, Dave. 2003. "The Making Of: Dust." Dave fohnston. January 26, 2003. https://www.johnsto.co.uk/design/making-dust/.

[35] Karhulahti, Veli-Matti. 2012. "Double Fine Adventure and the Double Hermeneutic Videogame." In Fun and Games' 2012. Toulouse, France.

[36] - - - 2015. "Adventures of Ludom: A Videogame Geneontology." PhD Thesis, Turku, Finland: University of Turku.

[37] Leino, Olli Tapio. 2012. "Death Loop as a Feature." Game Studies. The International Journal of Computer Game Research 12 (2). http://gamestudies.org/1202/articles/ death_loop_as_a_feature.

[38] Leino, Olli Tapio, and Sebastian Möring. 2015. "Authenticity Quest: On the Conditions of Possibility for 'Being Yourself' in a Computer Game." presented at the Conference of the Digital Games Research Association (DiGRA), Lüneburg.

[39] Mantzavinos, C. 2016. "Hermeneutics." In The Stanford Encyclopedia of Philosophy, edited by Edward N. Zalta, Winter 2016. Metaphysics Research Lab, Stanford University. https://plato.stanford.edu/archives/win2016/entries/hermeneutics/.

[40] McHale, Brian. 2001. Postmodernist Fiction. Reprinted. London: Routledge.

[41] Möring, Sebastian. 2013. Games and Metaphor - A Critical Analysis of the Metaphor Discourse in Game Studies. Copenhagen: IT University of Copenhagen. http: //bit.ly/1Gtcg4k.

[42] - - . 2016. "Understanding Single Player Computer Games as Experimental Systems." In Philosophy of Computer Games Conference. University of Malta, Malta. http://pocg2016.institutedigitalgames.com/site/assets/files/1015/moring_experimental_systems.pdf.

[43] Murray, Janet Horowitz. 1997. Hamlet on the Holodeck: The Future of Narrative in Cyberspace. Cambridge, MA: MIT Press.

[44] Nintendo EAD. 1990. Super Mario World. [Super Nintendo Entertainment System]. Kyoto, Japan: Nintendo.

[45] Obsidian Entertainment. 2010. Fallout: New Vegas. [Microsoft Windows; PlayStation 3; Xbox 360]. Bethesda Softworks.

[46] O'Donnell, Casey. 2014. Developer's Dilemma: The Secret World of Videogame Creators. Inside Technology. Cambridge, Massachusetts: The MIT Press.

[47] OED Online. 2014. "Heuristic, n. and Adj." OED Online Third Edition. Oxford University Press. http://www.oed.com/view/Entry/86554.

[48] Pias, Claus. 2004. "Action, Adventure, Desire. Interaction with PC Games." In Interactive Dramaturgies. New Approaches in Multimedia Content and Design, edited by Heide Heidebölling, 133-48. X.Media.Publishing. Berlin, Heidelberg, New York: Springer.

[49] Rusch, Doris C. 2009. "Mechanisms of the Soul - Tackling the Human Condition in Videogames." In Breaking New Ground: Innovation in Games, Play, Practice, and Theory. Uxbridge, UK: Brunel University. http://www.digra.org:8080/Plone/dl/ db/09287.01371.pdf.

[50] Square. 1997. Final Fantasy VII. [Windows PC]. Eidos Interactive.

[51] Takemoto. 2007. Kaizo Mario World. [Super Nintendo Entertainment System].

[52] Thatgamecompany. 2012. fourney. [Windows PC; PlayStation 4]. Sony Computer Entertainment.

[53] Valve. 2000. Counter-Strike. [Windows PC]. Sierra Entertainment.

[54] Zagal, José P., Michael Mateas, Clara Fernández-Vara, Brian Hochhalter, and Nolan Lichti. 2005. "Towards an Ontological Language for Game Analysis." In Proceedings of DiGRA 2005 Conference: Changing Views - Worlds in Play, 1-13. Vancouver: Digital Games Research Association DiGRA. http://www.digra.org/ $\mathrm{dl} / \mathrm{db} / 06276.09313$.pdf.

[55] ZeniMax Online Studios. 2014. The Elder Scrolls Online. [Windows PC; Mac]. Bethesda Softworks.

[56] Ziegfeld, Richard. "Interactive fiction: A new literary genre?" New Literary History 20.2 (1989): 341-372. 